\title{
Apresentação
}

Cleriston Izidro dos Anjos

Solange Estanislau dos Santos 2

Fernando llídio Ferreira ${ }^{3}$

\section{As lutas pela Educação Infantil: políticas, direitos e pedagogias}

O sonho de um mundo melhor nasce das entranhas do seu contrário. Por isso corremos o risco tanto de idealizarmos o mundo melhor, desgarrando-nos do nosso concreto, quanto de, demasiado 'aderidos' ao mundo concreto, submergirmo-nos no imobilismo fatalista (FREIRE, 2000, 133).

educação institucionalizada é frequentemente encarada como um fenômeno natural e não
como uma construção sócio histórica resultante da ação e do pensamento humanos, nos
domínios político, social, econômico, cultural, científico, pedagógico, profissional, etc. Tendencialmente, essa visão determinística conduz tanto à aceitação do status quo e da inércia política, como de políticas públicas, programas e ações, ativamente disseminados, tanto em escala nacional como global, em nome da "mudança da Educação". Esta mudança, cada vez mais global estandardizada, na qual participam organismos e programas internacionais, tais como o Banco Mundial, a Organização de Cooperação e de Desenvolvimento Econômico (OCDE) e o Programa Internacional de Avaliação de Estudantes (em inglês, PISA), tem vindo a ser operada mesmo debaixo dos nossos olhos, como algo inevitável, não enfrentando obstáculos de relevo em termos de resistências e de lutas por uma Educação inclusiva, plural e democrática.

Como revela a História, a educação é feita de avanços e recuos e não evolui de forma linear na prossecução dos valores da igualdade e da justiça social. O sentido hegemônico da mudança é o da difusão de uma educação adaptativa e instrumental, visando a adesão acrítica aos princípios da competitividade e do lucro que caracterizam a economia capitalista e não o da promoção de uma educação cidadã. As reestruturações curriculares feitas em algumas partes do mundo na atual década, às quais vem atrelado um conjunto de materiais, ditos pedagógico-didáticos e de apoio ao desenvolvimento curricular e à aprendizagem das crianças, produzidos por editoras e outros tipos de empresas, são exemplos que reforçam a lógica hegemônica da mudança da educação.

Embora a História mostre que os setores educativos menos valorizados, material e simbolicamente, no que toca a políticas, orçamento e reconhecimento públicos, têm sido os que abrangem crianças das faixas etárias mais baixas, as últimas décadas têm sido férteis na produção de uma visão diferente sobre a infância, as crianças e a Educação Infantil. Essa visão tem sido construída, quer pela via científica, por meio de estudos e pesquisas sobre e pelas crianças concebidas como atores sociais e, como tal, questionando a secundarização da

\footnotetext{
1 Doutor em Educação pela Universidade Federal de Alagoas. Professor Adjunto na Universidade Federal de Alagoas. Líder do Grupo de Estudos e Pesquisas em Pedagogias e Culturas Infantis. E-mail: cianjos@yahoo.com.br

2 Doutora em Educação pela Universidade Estadual de Campinas. Professora Adjunta na Universidade Federal de Alagoas. Líder do Grupo de Estudos e Pesquisas em Pedagogias e Culturas Infantis. E-mail: solestani13@yahoo.com.br

3 Doutor em Estudos da Criança pela Universidade do Minho. Professor Associado na Universidade do Minho, Portugal. E-mail: filidio@ie.uminho.pt
} 
educação das crianças dos 0 aos 6 anos de idade e reclamando a sua importância na vida das crianças, quer por movimentos, ações e mobilizações sociais que colocam a questão da Educação Infantil no plano dos direitos e da justiça social. Em relação a produção de conhecimento, é notório o interesse crescente de acadêmicos/as e pesquisadores/as, no campo da educação, em áreas como a psicologia, a pedagogia, a antropologia, a sociologia, as neurociências, entre outras, pelos estudos da infância, considerada, simultaneamente, uma etapa crucial de desenvolvimento e de aprendizagem e uma categoria geracional de natureza estrutural, como são as categorias gênero, raça, classe social, etc. Ou seja, ocorrem em simultâneo a afirmação de abordagens teóricoepistemológicas mais críticas, emancipatórias e instituintes, questionando a subordinação da ciência aos poderes dominantes instituídos, e as mobilizações e lutas protagonizadas por diversos movimentos sociais enquanto sujeitos políticos participantes da transformação social.

A subordinação da educação à economia, crescentemente dominada pela lógica financeira capitalista, está bem evidenciada em alguns programas e medidas de políticas públicas em educação. No Brasil, a proposta de criação do Programa Escola sem Partido representa um dos exemplos mais flagrantes de uma estratégia de despolitização da educação, expondo-a à penetração mais fácil de interesses e estratégias que lhe são estranhas. A introdução da "educação financeira" nas escolas é também um bom exemplo. Acresce a estes a invisibilidade das crianças nas políticas educacionais e a uniformização de propostas que desconsideram o que há de extraordinário nas crianças e nossas instituições de Educação Infantil.

Em síntese, o sentido dominante da mudança educacional tem hoje a particularidade de se realizar às escalas global, nacional e local, de forma interdependente, isomórfica e uniformizadora. Dentre as suas características e tendências, destacamos as seguintes: a reprodução e o aumento das desigualdades sociais e educativas ao invés de as reduzir; a falta de condições que garantam uma educação pública de qualidade para todos e todas; o desinvestimento, material e simbólico, da formação e do trabalho docente, cada vez mais reduzidos à dimensão técnico-instrumental e desinvestidos do sentido crítico e emancipatório; o recrudescimento de uma cultura de avaliação dos(as) estudantes, que se insinua atualmente, também, no campo da Educação Infantil, concebendo a avaliação como medição, comparação e homogeneização e, nessa medida, desrespeitando as diferenças e o pluralismo; o aumento da performatividade e do individualismo competitivo, reativando-se as ideologias meritocrática e tecnocrática, ao invés dos valores democráticos da cooperação, da inclusão e da cidadania no seio das instituições educativas e das práticas pedagógicas.

Apoiadas no discurso da inevitabilidade das suas propostas, em relação às quais afirmam que não há alternativas, essas estratégias alimentam o "pensamento único" (FOYER \& THIOLLET, 1998), também no campo educativo, que é por definição o espaço do pensamento plural e crítico. No entanto, o avanço destas estratégias não tem passado imune a lutas e resistências e à contraposição de alternativas feitas de sonho e utopia. Como diz Paulo Freire, "sem sonho e sem utopia, sem denúncia e sem anúncio, só resta o treinamento técnico a que a educação é reduzida" (FREIRE, 2000, p.124).

A abertura ao "ainda-não", ao conceito de "ainda-não consciente" de Bloch (2005), é essencial para o questionamento e a superação do pensamento único gerador do fatalismo e da resignação. É neste 
sentido que a obra de Boaventura de Sousa Santos assume especial relevância, no sentido da renovação da teoria crítica e da reivenção da emancipação social (SANTOS, 2007, p.28).

Muito do que não existe em nossa realidade é produzido ativamente como nãoexistente, e por isso a armadilha maior para nós é reduzir a realidade ao que existe. Assim, de imediato compartimos essa racionalidade preguiçosa, que realmente produz como ausente muita realidade que poderia estar presente.

À "razão indolente" este sociólogo contrapõe uma "sociologia insurgente", para a qual convergem a "Sociologia das Ausências" e a "Sociologia das Emergências", que constituem um "procedimento transgressivo, uma sociologia insurgente para tentar mostrar que o que não existe é produzido ativamente como não-existente, como uma alternativa não-crível, como uma alternativa descartável, invisível à realidade hegemônica do mundo". (SANTOS, 2007, p.28-9).

As lutas pela educação consistem em ações, movimentos e mobilizações sociais, enquanto formas de ação coletiva que buscam conquistar ou reconquistar um espaço social, no reconhecimento de que as estruturas sociais condicionam a ação humana, mas não a determinam completamente. É neste sentido que a sociedade constrói o seu futuro, tanto por via de mecanismos estruturais como através das suas próprias lutas sociais. Como argumenta Alain Touraine (2006, p.20), "falarmos sobre movimento social significa colocarmo-nos no ponto de vista dos atores, isto é, dos atores que são, ao mesmo tempo, conscientes do que têm em comum, ou seja, dos mecanismos de conflitos e dos interesses particulares que os definem uns contra os outros" (TOURAINE, 2006, p. 20).

Relacionados à Educação Infantil, destaca-se o Movimento de Luta pelas Creches, protagonizado pelas mães trabalhadoras, principalmente nas áreas urbanas, dada a sua necessidade de espaços de acolhimento adequado às crianças pequenas e aos bebês para que pudessem trabalhar. Este movimento foi importante nos anos de 1970, especialmente em São Paulo e em Belo Horizonte. Um segundo período da luta por creches situa-se na "transição democrática", na década de 1980, surgindo a primeira proposta brasileira para uma política pública de educação das crianças de 0 a 3 anos, proveniente da gestão (19861989) do Conselho Nacional dos Direitos da Mulher (CNDM), criado em 1985, e do Conselho Estadual da Condição Feminina (CECF de São Paulo), conforme afirma Pionório (2011). A reivindicação do direito à creche passou a ser feita não apenas pelas mães trabalhadoras, mas também pelo movimento feminista e pelos sindicatos, articulando a luta por igualdade de condições de trabalho entre homens e mulheres com a luta pelo direito à educação das crianças pequenas em espaços públicos e coletivos.

\footnotetext{
A luta por creche, no âmbito da implementação e expansão de uma educação infantil que respeitasse os direitos das crianças e das famílias, continuava a suscitar uma discussão que buscava refletir o direito a uma Educação Infantil de qualidade. $O$ fortalecimento de uma visão crítica que questionava o puro assistencialismo caracterizante das propostas de educação compensatória, levou até mesmo estudantes do curso de pedagogia a somar forças nas discussões políticas da pedagogia para esta modalidade educativa (DE ANGELO, 2010, p.132).
}

Ainda que a Educação infantil brasileira tenha tido grandes conquistas, designadamente, ser proclamada um direito da criança na Constituição de 1988, ser definida como primeira etapa da educação 
básica na Lei de Diretrizes e Bases da Educação Nacional (LDBEN 9394/96) e ser incluída ${ }^{4}$ no Fundo de Manutenção e Desenvolvimento da Educação Básica e de Valorização dos Profissionais da Educação (FUNDEB/2005), ainda estamos enfrentando várias batalhas e carecemos de mais movimentos e coletivos de lutas que reivindiquem as especificidades desta etapa da educação básica e não deixem que ela se transforme num espaço opressor e escolarizante para as crianças pequenas.

Mais recentemente, o Movimento pelas Creches foi recriado como "Movimento dos Sem Creche", também em cidades como São Paulo, destacando-se também, na atualidade, o Movimento Interfóruns de Educação Infantil do Brasil - MIEIB, nas lutas pela Educação Infantil.

O MIEIB representa um espaço de discussão e articulação, suprapartidário, composto por diversas instituições, órgãos e entidades comprometidas com a expansão e melhoria da qualidade da educação infantil no Brasil; constituiu-se por 25 Fóruns Estaduais e tem por finalidade defender coletivamente a garantia do direito das crianças de até seis anos ao acesso à Educação Infantil. Participam do Movimento todos os interessados na EI - órgãos governamentais na área da educação, assistência social, justiça, saúde e outros; ONGs; IES; conselhos estaduais e municipais de educação e direitos; representantes de creches e pré-escolas públicas e privadas; instituições de pesquisa; professoras, pesquisadoras e pesquisadores, família, comunidades, sindicatos, estudiosas e estudiosos e envolvidos na área (CANAVIEIRA; PALMEN, 2015, p.42).

Embora permeado por conflitos e contradições, esse tem sido um dos principais fóruns de debates e lutas pela Educação Infantil pública, gratuita e de qualidade, assim como espaço de enfrentamentos contra os retrocessos políticos atuais, dentre eles, a nova versão da Base Nacional Curricular Comum (BNCC) 5 que ignora a produção acadêmica e as discussões realizadas nas outras versões e a inclusão da Educação Infantil no PNAIC (Programa Nacional de Alfabetização na Idade Certa). Estamos passando por esses momentos de mais perdas quando ainda estamos tentando nos recuperar da Emenda Constitucional n ${ }^{\circ}$ 59, de 11 de novembro de 2009, que traz a obrigatoriedade de matrícula das crianças aos 4 anos de idade e o Ensino Fundamental de nove anos que incluiu as crianças de 6 anos. São derrotas que estamos sofrendo apesar de todas as batalhas travadas, mas que nos indicam a necessidade de continuarmos em frente lutando para que as crianças pequenas tenham garantidos seus direitos a espaços coletivos públicos e gratuitos que proporcionem experiências emancipatórias.

Este dossiê, que foi pensado para promover a reflexão, a discussão e o debate críticos em torno da temática das Lutas pela Educação Infantil, traz agora a lume um conjunto de artigos, da autoria de pesquisadores/as nacionais e internacionais, que problematizam questões dos campos dos direitos, das políticas, das pedagogias e da formação docente na Educação Infantil, provocadas pelo atual cenário político e social. De maneira geral, trazem contribuições muito relevantes para superar uma visão das crianças confinadas historicamente ao espaço privado, colocando-as no espaço público como sujeitos de direitos, atores sociais competentes, com voz e participantes nas escolhas e decisões que lhes dizem respeito. São abordadas temáticas que envolvem a intersecção entre classe social, etnia, gênero, sexualidade, religião e abarcam debates em torno dos movimentos sociais, das lutas feministas, da ${ }^{4}$ Essa inclusão se deu devido a pressão popular no movimento que ficou conhecido como "Movimento das fraldas pintadas".
5 5ara mais informações sobre o debate em torno da BNCC, sugere-se a leitura do dossiê: "Educação Infantil e Base Nacional Comum Curricular: questões para o debate": http://www.seer.ufal.br/index.php/debateseducacao/issue/view/213/showToc 
militância acadêmica e das disputas históricas pelo direito a educação pública, laica, gratuita e de qualidade para todas as crianças.

O conjunto de artigos, escritos com a participação de muitas mãos e sendo portadores de diversas vozes que lutam pela Educação Infantil, são oriundos de contribuições de autores/as de diversas instituições do Brasil, Portugal e Itália que, também a partir da escrita, desenvolvem sua militância em defesa da Educação Infantil.

No primeiro artigo, intitulado "Quale educazione da zero a sei anni? Prospettive legislative e nuove sfide culturali per i servizi educativi italiani”, Agnese Infantino (Università degli Studi di MilanoBicocca, Itália), apresenta e analisa a perspectiva do "Sistema integrado de educação das crianças de 0 a 6 anos de idade, a partir da Lei 107/2015 e do Decreto 65/2017. Nesse contexto, a autora aborda o tema da continuidade educacional e uma cultura educacional compartilhada entre creche e jardim de infância como dimensões importantes dessa perspectiva. Além disso, apresenta aspectos concernentes aos desafios da proposta, especialmente no que dizem respeito aos métodos de coordenação e os processos de formação de profissionalismo de educadores/as e professores/as.

No segundo artigo, intitulado "Le Associazioni delle donne e i diritti dell'infanzia in Italia (18611930)", Gabriella Seveso (Università degli Studi di Milano-Bicocca, Itália) e Daniela Finco (Universidade Federal de São Paulo, Brasil) apresentam elementos para a reconstrução da história dos direitos à educação para a primeira infância na Itália no período entre a Unificação da Itália (1861) e as primeiras décadas do século XX, cuja difusão institucional está vinculada a associações feministas e as iniciativas de pensadores iluminados. A partir dessa história, recuperam a necessidade da garantia de instituições com fins educativos para crianças pequenas ao invés de instituições com finalidade assistencial. Apontam ainda para o fato de que a associação feminista também lutou para a formação docente adequada para os/as profissionais de Educação Infantil e apresentam indícios de retrocessos, como no caso da política governamental que fundou a Opera Nazionale Maternità e Infanzia, com objetivos de controle da saúde e assistência.

No terceiro artigo, intitulado "Educazione all'arte come esperienza, comunicazione, sperimentazione e documentazione: Un percorso di ricerca in Italia nei servizi educativi”, Franca Giuliana Zuccoli (Università Milano-Bicocca, Itália), discute a importância da arte na educação de crianças pequenas no contexto italiano, considerando três dimensões: i) a conexão com o mundo da arte contemporânea, com a sua comunicação política liderada; ii) a importância da experiência de laboratório, organização de espaços, materiais e experimentação e; iii) o potencial da documentação como possibilidade reflexiva metacognitiva para crianças e adultos.

No quarto artigo, intitulado "Avaliação das políticas de Educação Infantil no Brasil: avanços e retrocessos", Lisete Regina Gomes Arelaro (Faculdade de Educação da Universidade de São Paulo, Brasil), analisa as principais políticas educacionais estabelecidas para a educação básica no Brasil no século XXI, destinadas a Educação Infantil ou com alguma repercussão para esta etapa. Avalia a implementação das mesmas sob três critérios: a democratização do acesso, a qualidade do atendimento e o estímulo à gestão democrática e suas repercussões. 
No quinto artigo, intitulado "A emergência da criança como sujeito de direitos na Educação Infantil", Ana Katia Alves dos Santos (Universidade Federal da Bahia, Brasil), apresenta reflexões sobre a emergência da Criança como Sujeito de Direitos na Educação Infantil a partir do reconhecimento da necessidade de implantação efetiva do Estatuto da Criança e do Adolescente (ECA) e outros instrumentos legais relativos a garantia de direitos das crianças, tendo em vista as precárias condições materiais e formativas a que estão submetidas as crianças pequenas.

No sexto artigo, intitulado “A Educação encontra a Arte: Apontamentos Político Pedagógicos sobre Direitos e Pequena Infância", Sandra Regina Simonis Richter (Universidade de Santa Cruz do Sul, Brasil), Adriana Alves da Silva (Universidade do Estado de Santa Catarina, Brasil) e Ana Lúcia Goulart de Faria (Universidade Estadual de Campinas, Brasil), problematizam as bases exclusivamente científicas da Pedagogia e seu tecnicismo estrutural - a didática - na tentativa de, com a arte, preencher a lacuna da formação docente e de contribuir com a emergência política de uma outra Pedagogia da Infância. Para isso, discutem "as primeiras aprendizagens" por meio de filósofos interessados na arte e na vida humana, fazem uma crítica à pedagogia escolarizante como única forma de garantir o direito à educação e discutem possíveis lacunas na formação do pedagogo(a) que convive e trabalha com crianças pequenas, especialmente no que se refere à arte. $O$ destaque está na defesa de uma pedagogia que não separa experiência e saber, corpo e mente, pensamento e ação no mundo.

No sétimo artigo, intitulado "Pesquisar e educar para as relações étnico-raciais na educação infantil: uma luta contra o ruído do silêncio", Nanci Helena Rebouças Franco (Universidade Federal da Bahia, Brasil) e Fernando Ilídio da Silva Ferreira (Universidade do Minho, Portugal) analisam a importância da educação para as relações étnico-raciais na Educação Infantil, a partir de dados coletados em Salvador (Brasil) fazendo um contraponto com uma experiência de pesquisa em Braga (Portugal). As discussões apontam para a importância da educação para as relações raciais e a necessidade de rompimento com o silêncio dos adultos no espaço da família e das instituições de Educação Infantil. Diante disso, a educação na/para a diversidade se coloca como um desafio/possibilidade de prática pedagógica promotora da igualdade na Educação Infantil, na perspectiva da compreensão das crianças enquanto sujeitos históricos, sociais, culturais e portadores de direitos, e da construção de uma sociedade mais humana e com mais equidade.

No oitavo artigo, intitulado "Movimentos sociais e a formação política de mulheres na luta por creches: a experiência do 'Artcreche’ em São Gonçalo”, Maria Tereza Goudard Tavares (Universidade do Estado do Rio de Janeiro, Brasil) apresenta contributos concernentes à luta de movimentos sociais urbanos, de modo particular o Movimento de Articulação das Creches de São Gonçalo (ArtCreche). O foco de investigação apresentado neste artigo está na luta de mulheres pelo direito à creche a partir de uma pesquisa qualitativa, de cunho participante, priorizando uma análise do poder local em diálogo com o conceito de hegemonia popular.

No nono artigo, intitulado "Políticas Públicas e Direitos das Crianças: uma reflexão a partir da perspectiva étnico-racial", Fabiana de Oliveira (Universidade Federal de Alfenas, Brasil) e Anete Abramowicz (Universidade Federal de São Carlos, Brasil), afirmam que, embora a abertura para as discussões raciais no 
Brasil tenha se ampliado nos últimos anos, a discriminação racial constitui o duplo fator de desigualdade social para as crianças, na medida em que são silenciadas por serem pequenas e por serem negras. Diante desta constatação, as autoras apresentam reflexões relacionadas às políticas públicas e aos direitos das crianças negras à educação. A relevância para o desenvolvimento do trabalho se pauta na escassez de estudos envolvendo políticas públicas e educação e infância a partir dos recortes de idade e raça no Brasil.

No décimo artigo, intitulado "A relação entre creche e famílias: entraves que permanecem há décadas", Telma Vitoria (Universidade Federal de Alagoas, Brasil) apresenta os principais resultados de uma pesquisa realizada em 1997 que, além de não ter sido publicada, apresenta discussão pertinente e atual especialmente no que se refere às lutas por creches e os direitos das crianças e das famílias. Nesse contexto, a autora contribui para o registro histórico e para a reflexão sobre o papel das creches no contexto social mais amplo, na medida em que focaliza a relação entre as creches e as famílias atendidas, mostrando que algumas problemáticas dessa relação, identificadas há trinta anos (1997-2017), ainda podem ser observadas nesses cotidianos.

No décimo primeiro artigo, intitulado "Mudanças, persistências e resistências formação para docência em creches e pré-escolas", Sílvia Adriana Rodrigues (Universidade Federal do Mato Grosso do Sul, Brasil), apresenta uma discussão sobre identidade e desenvolvimento profissional dos docentes da Educação Infantil, partindo do princípio de que um dos desafios do campo está nas concepções equivocadas do que é ser professor de crianças pequenas. Para a autora, embora a Educação Infantil tenha sido reconhecida como primeira etapa da Educação Básica brasileira e já tenha um ordenamento político e pedagógico que oriente o trabalho, o cotidiano em diversos contextos ainda não reflete estes avanços.

No décimo segundo artigo, intitulado "Educação Infantil no cenário brasileiro pós golpe parlamentar: políticas públicas e avaliação”, Ângela Scalabrin Coutinho (Universidade Federal do Paraná, Brasil) e Catarina Moro (Universidade Federal do Paraná, Brasil), analisam as mudanças nas proposições das políticas públicas de Educação Infantil, com foco nas políticas relativas à avaliação concernente a esta etapa, em decorrência da troca de governo ocorrida no Brasil em 2016. As autoras apresentam o percurso recente de elaboração de uma política de avaliação para essa etapa educacional, destacando as metas e estratégias do Plano Nacional de Educação (PNE) e a relacionam com outras políticas em curso, como a definição de uma Base Nacional Comum Curricular (BNCC). Consideram, ainda, que, a revogação da portaria que definia o Sistema Nacional de Avaliação da Educação Básica (SINAEB), que incluía a Avaliação da Educação Infantil (ANEI) e a apresentação de uma terceira versão da BNCC, focada em uma perspectiva curricular baseada em competências e habilidades e com ênfase na escrita na Educação Infantil, coloca em risco o processo de definição de uma política avaliativa descentrada do desempenho individual das crianças e preocupada com a qualidade da oferta da educação. Além disso, as autoras chamam a atenção para a problemática das alianças estabelecidas na definição das políticas educacionais, tendo em vista a identificação da participação de entidades privadas não só na execução das políticas, mas na sua formulação, o que aponta para uma lógica privatista de governo. 
No último artigo, intitulado "Participação infantil e debate democrático: aproximações pelo campo da Educação Infantil", Fabiana Oliveira Canavieira (Universidade Federal do Maranhão, Brasil) e Maria Carmem Silveira Barbosa (Universidade Federal do Rio Grande do Sul, Brasil) discutem os modos pelos quais a temática da democracia e seus princípios se apresentam no cenário acadêmico e político pedagógico da Educação Infantil a partir do contexto histórico e político-social brasileiro contemporâneo. As autoras abordam a temática da democratização da e na Educação Infantil, fazendo a diferenciação entre elas e apresentando possibilidades para que as discussões avancem no sentido de garantir o protagonismo infantil.

É inegável a abrangência e a qualidade das várias contribuições, de pesquisadores/as de diferentes países, para este dossiê, apesar de ainda ficar muito por dizer e fazer no campo das Lutas pela Educação Infantil. Como é defendido numa obra coletiva recente (GEPEDISC, 2015), os/as autores/as sustentam que é necessário pensar as infâncias e os movimentos sociais numa interlocução entre os estudos póscolonialistas e a Sociologia da Infância, sem abandonar o legado marxista. Nesse sentido, sugerem uma focalização na participação nas lutas para garantia do direito das crianças pequenas, quilombolas, sem terrinhas e das crianças pequenininhas negras na garantia do direito à educação infantil, inserida no debate mais amplo que inclui a arte, as culturas infantis e as lutas políticas. Assim, a descolonização do currículo, da pedagogia, das políticas, e mesmo dos direitos supostamente universais, constitui um desafio na Educação Infantil, do mesmo modo como o questionamento do adultocentrismo colonizador dos mundos sociais e culturais das crianças. Como refere Gomes (2012), é importante salientar a contribuição proporcionada pela compreensão das rupturas epistemológicas e culturais trazidas pela questão racial na educação brasileira, assim como pelas questões de gênero, da infância e da juventude, das lutas dos movimentos sociais e dos grupos populares marginalizadas e discriminadas no cotidiano da escola mas é necessário ir mais longe nas rupturas epistemológicas e culturais no campo educacional, como apela este autor (GOMES, 2012).

É necessário ir mais longe como, por exemplo, na promoção da participação cidadã das próprias crianças nos movimentos sociais, como parceiras e protagonistas. Fúlvia Rosemberg (2011) chama a atenção para o fato de o sujeito dos movimentos sociais ser a pessoa adulta, considerando que os movimentos sociais brasileiros contemporâneos, que se mobilizam por igualdade de oportunidades da perspectiva de gênero e raça-etnia, são adultocêntricos, pois seus sujeitos políticos são adultos, quando muito, jovens e adultos (ROSEMBERG, 2011). Assim, um desafio maior que se coloca no plano das lutas pela Educação Infantil é interrogar o lugar das crianças enquanto sujeitos políticos. A proposta de Catarina Tomás (2007, p.iv) reveste-se de grande relevância e atualidade a respeito deste desafio: "escutar e ler, no sentido de interpretar, os discursos das crianças sobre os seus direitos e as representações que têm sobre si, sobre as outras crianças, sobre os direitos da criança e sobre o mundo".

Esperamos que o conjunto de reflexões expostas neste dossiê contribua para alimentar as lutas em defesa da Educação Infantil pública, gratuita, laica e de qualidade para todas as crianças. Que as mãos e as vozes que contribuíram para a constituição desse dossiê se unam a tantas outras, fortalecendo seus protagonistas nestes tempos difíceis em que vivemos. 
Concluímos retomando a perspetiva de Boaventura de Sousa Santos da "sociologia das ausências" e da "sociologia das emergências" (SANTOS, 2007), pois através delas podemos observar, imaginar e apreender outras realidades possíveis e emergentes. A Sociologia das Ausências torna presentes experiências disponíveis, mas que estão produzidas como ausentes e é necessário fazer presentes, e a Sociologia das Emergências produz experiências possíveis, que não estão dadas porque não existem alternativas para isso, mas são possíveis e já existem como emergência. Assim, o autor defende que na Sociologia das Emergências devemos fazer uma ampliação simbólica de pequenos movimentos sociais, de pequenas ações coletivas (SANTOS, 2007). Este é um grande desafio ético, político e pedagógico que pode ser mobilizador dos diversos atores políticos, acadêmicos, pesquisadores, profissionais, ativistas, adultos e crianças - que constroem e reconstroem a Educação Infantil quotidianamente, numa perspectiva da Educação Infantil em movimento.

\section{Agradecimentos}

Registramos nossos agradecimentos a Andréa Duarte (Instituto das Comunidades Educativas, Portugal), Márcia Buss-Simão (Revista Zero-a-seis) e Ana Lúcia Goulart de Faria (Universidade Estadual de Campinas, Brasil) pelas contribuições na organização deste dossiê, além de todos/as autores/as que se dispuseram a compor esta publicação.

\section{Referências}

BLOCH, E. O princípio esperança. Rio de Janeiro: UERJ/Contraponto, 2005. v. 1.

CANAVIEIRA, F. O.; PALMEN, S. H. C. Movimentos sociais e a luta pela educação infantil. In: GEPEDISC-Culturas Infantis. Infâncias e movimentos sociais. Campinas,SP: Edições Leitura Crítica, 2015, p.33-49. Disponível em: www.bibliotecadigital.unicamp.br/document/?down=73885

DE ANGELO, A. Educação Infantil no contexto dos movimentos sociais: duas leituras possíveis. Especiaria - Cadernos de Ciências Humanas. Ilhéus/BA, vs. 12 e 13, ns. 22 e 23, jul./dez. 2009 e jan./jun. 2010, p. 123-153.

FOYER, J. \& THIOLLET, J.-P. La Pensée unique. Economica. Paris: JM. Chardon \& D.Lensel Ed., 1998.

FREIRE, P. Pedagogia da indignação: cartas pedagógicas e outros escritos. São Paulo: Editora Unesp, 2000. 
GEPEDISC- Culturas Infantis. Infâncias e Movimentos Sociais. Campinas - SP: Edições Leitura Crítica, 2015.

GHON, M. G. "Movimentos Sociais e Lutas pela Educação no Brasil: Experiências e Desafios na Atualidade" Conferência de Encerramento da Reunião Científica Regional da ANPED "Educação, movimentos sociais e políticas governamentais”, 24-27 de julho de 2016, UFPR, Curitiba, Paraná.

GOMES, N. L. Relações étnico-raciais, educação e descolonização dos currículos. Currículo sem Fronteiras, v.12, n.1, pp. 98-109, Jan/Abr 2012.

PIONÓRIO, M. A. A. O Movimento Feminista e sua contribuição para a Educação Infantil no Brasil. Revista Parâmetro, 25 jan. 2011.

ROSEMBERG, F. A criança pequena e o direito à creche no contexto dos debates sobre infância e relações raciais. In: ABRAMOWICZ, Anete, et.al. Educação infantil, igualdade racial e diversidade: aspectos políticos, jurídicos, conceituais. São Paulo, CEERT, 2012, p. 11-46.

SANTOS, B. S. Renovar a teoria crítica e reinventar a emancipação social. Trad.: Mouza Benedito. São Paulo: Boitempo, 2007.

TOMÁS, C. A. Há muitos mundos no mundo...direitos das crianças, cosmopolitismo infantil movimentos sociais de crianças: diálogos entre crianças de Portugal e Brasil. 2007. Tese de Doutoramento em Estudos da Criança, especialidade de Sociologia da Infância. Braga: Universidade do Minho

TOURAINE, A. Na fronteira dos movimentos sociais. Sociedade e Estado, Brasília, v. 21, n. 1, p. 17-28, jan./abr., 2006. 